\title{
Synthesis of Syndiotactic Poly(vinyl alcohol) from Fluorine-Containing Vinyl Esters
}

\author{
Kazunobu Yamada, ${ }^{\dagger}$ Tamaki Nakano, ${ }^{*}$ and Yoshio OKamoto $*,+\dagger$ \\ Joint Research Center for Precision Polymerization (JRCPP)-Japan Chemical Innovation \\ Institute (JCII), Graduate School of Engineering, Nagoya University, \\ Furo-cho, Chikusa-ku, Nagoya 464-8603, Japan \\ * Department of Applied Chemistry, Graduate School of Engineering, Nagoya University, \\ Furo-cho, Chikusa-ku, Nagoya 464-8603, Japan
}

(Received January 21, 1998)

\begin{abstract}
Radical polymerization of vinyl pivalate (VPi), vinyl trifluoroacetate (VTFAc), vinyl 2,2-bis(trifluoromethyl)propionate (1), vinyl 5H-octafluorovalerate (2), vinyl 7H-dodecafluoroheptanoate (3), and vinyl 9H-hexadecafluorononanoate (4) was carried out and the tacticity of the resulting polymers was determined by ${ }^{1} \mathrm{H}$ or ${ }^{13} \mathrm{C}$ NMR analysis of poly(vinyl alcohol) (PVA) derived from the original polymers. In the bulk polymerization at $60^{\circ} \mathrm{C}$, the order of diad syndiotacticity of the polymers was poly(VTFAc) $(57 \%)<$ poly $(\mathrm{VPi})(60 \%)<$ poly-2, poly-3, poly-4 $(61-62 \%)<$ poly-1 $(65 \%)$, suggesting that steric and electrostatic effects of the fluorine-containing side groups of monomers influence the syndiotactic specificity of propagation reaction. A syndiotacticity of $69 \%$ was achieved by solution polymerization of 1 in tetrahydrofuran at $0^{\circ} \mathrm{C}$. This is the highest syndiotacticity reported for the radical polymerization of vinyl esters at $0^{\circ} \mathrm{C}$ or higher temperatures. The difference of activation enthalpy $\left(\Delta H^{\ddagger}\right)$ and activation entropy $\left(\Delta S^{\ddagger}\right)$ between isotactic and syndiotactic propagations in bulk polymerization of 1 were estimated to be $460 \mathrm{cal} \mathrm{mol}^{-1}$ and $0.2 \mathrm{cal} \mathrm{deg}^{-1} \mathrm{~mol}^{-1}$, respectively. Solvolysis rates of the vinyl esters and their polymers were also examined.

KEY WORDS Poly(vinyl alcohol) / Radical Polymerization / Tacticity / Vinyl Ester / Fluorocarbon / Electorostatic Repulsion / Solvolysis /
\end{abstract}

Poly(vinyl alcohol) (PVA) is an important polymer used for various purposes including fiber, film, and adhesive. Physical and chemical properties of PVA are greatly affected by its stereoregularity and PVA with a high syndiotacticity shows enhanced heat-resistance, strength, and modulus. ${ }^{1}$ PVA is generally prepared by radical polymerization of vinyl esters such as vinyl acetate (VAc) and vinyl pivalate (VPi) followed by saponification of the obtained polymers. Diad syndiotacticity of the PVA derived from poly(VAc) prepared by bulk radical polymerization of VAc is $\mathrm{ca} .53 \%$ and polymerization conditions have only little effect on the stereochemistry of polymerization. ${ }^{2-4} \mathrm{VPi}$ and vinyl trifluoroacetate (VTFAc) are known to lead to the polymers with higher syndiotacticity compared with poly(VAc) obtained under similar conditions. ${ }^{5-9}$

Recently, Fukae et al. ${ }^{8}$ obtained PVA with a diad syndiotacticity of $69 \%$ and a melting point of $258^{\circ} \mathrm{C}$ by the radical polymerization of VPi in $n$-hexane and subsequent saponification of the poly(VPi). This method requires low polymerization temperatures such as $-40^{\circ} \mathrm{C}$ and therefore is not advantageous from the view point of industrial application. Free-radical polymerization of vinyl diphenylacetate also affords a syndiotactic polymer (diad 67.5\%). Although high stereospecificity can be achieved in the polymerization at $40^{\circ} \mathrm{C}$, molecular weight $\left(\bar{M}_{n}\right)$ of the polymer is limited to less than $1.0 \times 10^{4} .{ }^{10}$

In the present work, we carried out the polymerization of VPi, VTFAc, vinyl 2,2-bis(trifluoromethyl)propionate (1), vinyl $5 \mathrm{H}$-octafluorovalerate (2), vinyl $7 \mathrm{H}$-dodecafluoroheptanoate (3), and vinyl 9H-hexadecafluorononanoate (4) bearing bulky fluorocarbon side groups

in search for a method of syndiotactic PVA synthesis. 3 has been reported to give a polymer with $78 \%$ diad syndiotacticity, but the melting point of PVA derived from the poly-3 was $236^{\circ} \mathrm{C}$ which suggests an atactic structure. Stimulated by this report, we investigated the stereochemistry of the polymerization of a series of fluorocarbon monomers including 3.

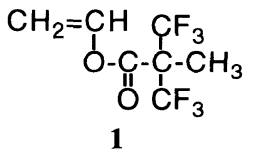

\section{EXPERIMENTAL}

\section{Materials}

2,2-Bis(trifluoromethyl)propionic acid, 5H-octafluorovaleric acid, 7H-dodecafluoroheptanoic acid, and 9H-hexadecafluorononanoic acid were purchased from Daikin Co. VTFAc (Aldrich), VPi (Wako), and VAc (Wako) were purified by distillation immediately before use. 2,2'-Azobisisobutyronitrile (AIBN) and benzoyl peroxide (BPO) were purified by recrystallization from methanol. All solvents were purified by distillation immediately before use. The other reagents were purified by usual methods.

\section{Synthesis of Vinyl Esters}

1- 4 were synthesized by the reaction of corresponding carboxylic acid with acetylene according to the method of Haas et al. ${ }^{12}$ A typical procedure is described below

† On leave from $R \& D$ Center, Unitika Ltd., 23 Kozakura, Uji, Kyoto 611-0021, Japan.

${ }^{\dagger+}$ To whom correspondence should be addressed. 
for 1. In a $100-\mathrm{mL}$ two-necked round bottom flask equipped with a gas introducing tube and a condenser, $49.2 \mathrm{~g}$ (200 mmol) of 2,2-bis(trifluoromethyl)propionic acid was placed and melted by heating at $120^{\circ} \mathrm{C}$. Mercury oxide (I) $(4.0 \mathrm{~g})$ and hydroquinone $(0.02 \mathrm{~g})$ were added and the mixture was vigorously stirred. Gasseous acetylene purified by passing through a cooling trap, a washing bottle containing sulfuric acid, and a soda-lime tube, was introduced into the mixture. The reaction mixture was immediately cooled to $80^{\circ} \mathrm{C}$, allowed to stand for $4 \mathrm{~h}$, and then cooled to room temperature. The insoluble solid was removed with a centrifuge and the supernatant liquid was distilled twice to give 1. 1; yield $38 \%$, bp $95-96^{\circ} \mathrm{C} / 760 \mathrm{mmHg}, d^{20} 1.38,{ }^{1} \mathrm{H}$ NMR $\left(\mathrm{CDCl}_{3}\right) \delta 1.74(\mathrm{~s}, 3 \mathrm{H}), 4.82(\mathrm{q}, 1 \mathrm{H}), 5.11(\mathrm{q}, 1 \mathrm{H}), 7.26$ (q, $1 \mathrm{H}) .2$; yield $28 \%$, bp $62^{\circ} \mathrm{C} / 56 \mathrm{mmHg}, d^{20} 1.53,{ }^{1} \mathrm{H}$ NMR $\left(\mathrm{CDCl}_{3}\right) \delta 4.93(\mathrm{q}, 1 \mathrm{H}), 5.23(\mathrm{q}, 1 \mathrm{H}), 6.07$ $\left(J_{\mathrm{HF}}=52 \mathrm{~Hz}, 1 \mathrm{H}\right), 7.27(\mathrm{q}, 1 \mathrm{H}) .3$; yield $14 \%$, bp 63$64^{\circ} \mathrm{C} / 13 \mathrm{mmHg}, d^{20} 1.63,{ }^{1} \mathrm{H}$ NMR $\left(\mathrm{CDCl}_{3}\right) \delta 4.94$ (q, $1 \mathrm{H}), 5.24(\mathrm{q}, 1 \mathrm{H}), 6.05\left(J_{\mathrm{HF}}=52 \mathrm{~Hz}, 1 \mathrm{H}\right), 7.27(\mathrm{q}, 1 \mathrm{H})$. 4; yield $15 \%$, bp $74-75^{\circ} \mathrm{C} / 5 \mathrm{mmHg}, d^{20} 1.71,{ }^{1} \mathrm{H}$ NMR $\left(\mathrm{CDCl}_{3}\right) \delta 4.94(\mathrm{q}, 1 \mathrm{H}), 5.24(\mathrm{q}, 1 \mathrm{H}), 6.06\left(J_{\mathrm{HF}}=52 \mathrm{~Hz}\right.$, $1 \mathrm{H}), 7.28(\mathrm{q}, 1 \mathrm{H})$.

\section{Polymerization}

Polymerization was carried out under dry nitrogen in a dried glass ampule equipped with a three-way stopcock using AIBN or BPO as an initiator at $0-80^{\circ} \mathrm{C}$. Polymerization at $20^{\circ} \mathrm{C}$ or lower temperature was carried out under UV light irradiation (400W high pressure mercury lamp). Monomer conversion was determined by ${ }^{1} \mathrm{H}$ NMR analysis of a polymerization mixture in acetone- $d_{6}$ at room temperature. Reaction products were diluted by acetone, precipitated into $n$-hexane, filtered, and dried under vacuum at $50^{\circ} \mathrm{C}$. Poly(vinyl ester)s were saponified to yield PVA as follows. To a solution of poly(vinyl ester)s $(1 \mathrm{~g})$ in tetrahydrofuran $(45 \mathrm{~mL})$ for poly-1 or methanol $(45 \mathrm{~mL})$ for poly-2-4, $10 \% \mathrm{NaOH}$ in methanol $(5 \mathrm{~mL})$ was added, and the mixture was stirred for $2 \mathrm{~h}$ at $40^{\circ} \mathrm{C}$. Saponification of poly(VPi) was perform- ed as reported. ${ }^{13}$ PVAs obtained were collected by filtration, washed with methanol, and dried under vacuum.

\section{Solvolysis of Monomers and Polymers}

Methanolysis of the vinyl ester monomers was performed with $0.55 \mathrm{mmol}$ of a monomer dissolved in $0.9 \mathrm{~mL}$ of methanol- $d_{4}(99.8 \% \mathrm{D}$ atom) containing $10 \mathrm{ppm}$ of $\mathrm{NaOH}$ in an $\mathrm{NMR}$ tube at $20^{\circ} \mathrm{C}$. The reaction was directly monitored by ${ }^{1} \mathrm{H}$ NMR spectroscopy. Saponification of a poly(vinyl ester) was performed using $1 \mathrm{mmol}$ (monomeric residue) of polymer. To a polymer solution in acetone $(9 \mathrm{~mL}), 0.2 \% \mathrm{KOH}$ in methanol $(1 \mathrm{~mL})$ was added and the mixture was stirred at $20^{\circ} \mathrm{C}$. The reaction mixture was precipitated into diethyl ether containing a small amount of acetic acid, filtered, and dried under vacuum. The degree of hydrolysis was determined by ${ }^{1} \mathrm{H}$ NMR analysis of the products in dimethylsulfoxide- $d_{6}$ (DMSO- $d_{6}$ ) at room temperature.

\section{Measurements}

Number average molecular weight $\left(\bar{M}_{n}\right)$ and polydispersity $\left(\bar{M}_{w} / \bar{M}_{n}\right)$ of the poly(vinyl ester)s were determined by size-exclusion chromatography (SEC) calibrated with polystyrene standards using a JASCO PU-980 pump equipped with a JASCO RI-930 detector and TSKgel $\mathrm{GMH}_{\mathrm{HR}}-\mathrm{H}$ and $\mathrm{G} 3000 \mathrm{H}_{\mathrm{HR}}$ columns (eluent; tetrahydrofuran, temperature; $40^{\circ} \mathrm{C}$ ). Triad tacticity of PVA was determined by ${ }^{1} \mathrm{H}$ NMR or ${ }^{13} \mathrm{C}$ NMR spectra recorded on a Varian Gemini 2000 spectrometer (400 $\mathrm{MHz}$ for $\left.{ }^{1} \mathrm{H}\right)$ or UNITY-INOVA $\left(500 \mathrm{MHz}\right.$ for $\left.{ }^{1} \mathrm{H}\right)$ in DMSO- $d_{6}$ at room temperature $\left({ }^{1} \mathrm{H}\right)$ or $100{ }^{\circ} \mathrm{C}\left({ }^{13} \mathrm{C}\right)$. Diad tacticity was calculated from triad tacticity by the following equations:

$$
m=m m+(m r) / 2, \quad r=r r+(m r) / 2
$$

\section{RESULTS AND DISCUSSION}

\section{Effects of Side Chains of Vinyl Esters on Tacticity}

Table I shows the results of bulk polymerization of

Table I. Radical bulk polymerization of vinyl esters containing fluorocarbon substituents ${ }^{\mathrm{a}}$

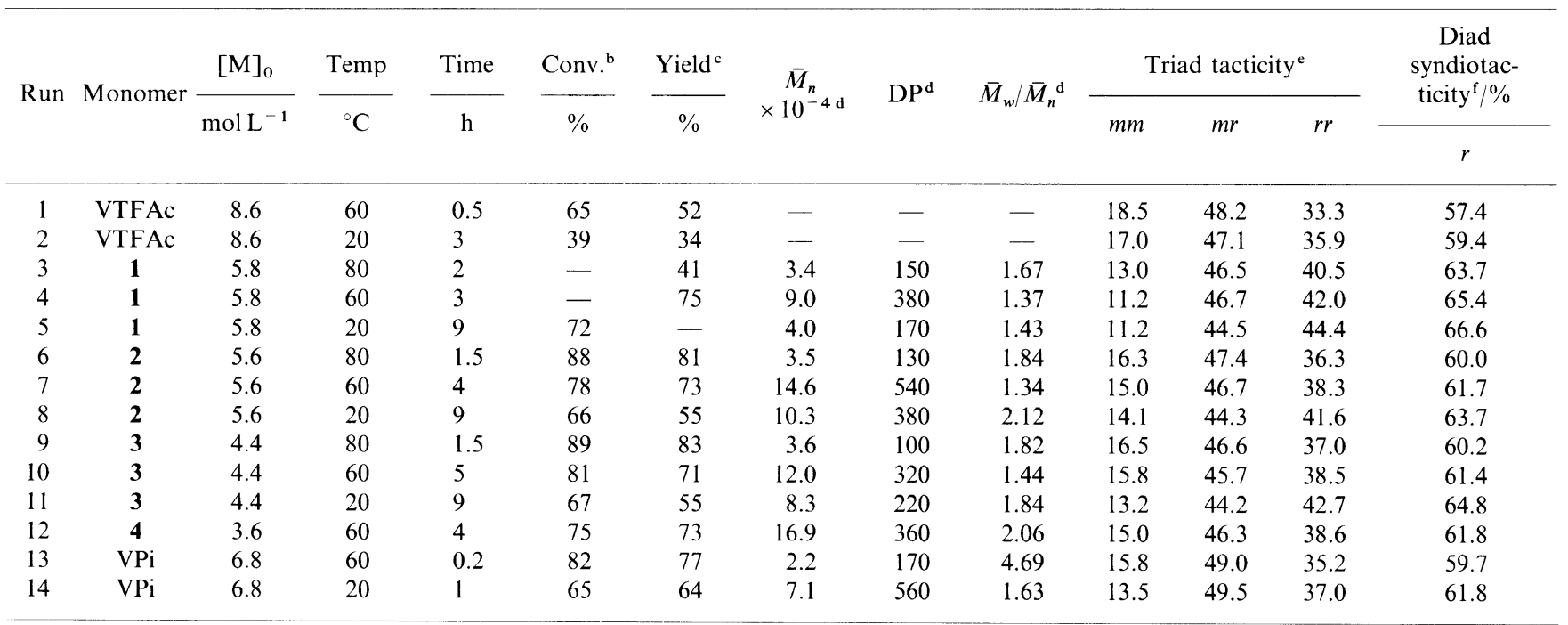

${ }^{a}$ Initiator: AIBN $(0.15 \mathrm{M})$. Polymerization at $20^{\circ} \mathrm{C}$ was conducted under UV light irradiation. ${ }^{\mathrm{b}}$ Determined by ${ }^{1} \mathrm{H}$ NMR in acetone- $d_{6}$. ${ }^{\mathrm{c}} n$-Hexane-insoluble part. ${ }^{\mathrm{d}}$ Determined by GPC (polystyrene standard) of original polymers in THF. ${ }^{\mathrm{e}}$ Determined by ${ }^{1} \mathrm{H}$ NMR of PVA in DMSO- $d_{6} . \quad{ }^{\mathrm{f}}$ Calculated based on triad tacticity $(r=r r+r m / 2)$. 
VTFAc, 1-4, and VPi. All polymerizations gave polymers rich in syndiotacticity (diad). $\mathbf{3}$ afforded a polymer with a diad syndiotacticity of only $64.8 \%$ under reaction conditions similar to those in other reports. ${ }^{11}$ Therefore, the reported syndiotacticity $(78 \%)$ might possibly be erroneous. The tacticity of the polymers depended on the structure of the starting monomer and the order of diad syndiotacticity of PVA derived from the poly(vinyl ester)s obtained at $60^{\circ} \mathrm{C}$ was poly(VTFAc) $(57 \%)<$ poly(VPi) $(60 \%)<$ poly-2, poly-3, poly-4 $(61-62 \%)<$ poly-1 $(65 \%)$. The same tendency was observed for the polymerization at $20^{\circ} \mathrm{C}$ and $80^{\circ} \mathrm{C}$. At all temperatures, the polymerization of $\mathbf{1}$ resulted in the highest syndiotacticity. In spite of the different lengths of fluorocarbon side chains in 2-4, the monomers afforded polymers with similar syndiotacticity which was slightly higher than that of the poly( $\mathrm{VPi})$. A bulkier monomer seems to give a polymer with a higher syndiotacticity. However, since 2 -4, which may be sterically less bulky than VPi, gave polymers with a higher syndiotacticity than poly(VPi), electrostatic repulsion based on $-\mathrm{CF}_{2}-$ groups may be another driving force for the syndiotactic-specific propagation. These results suggest that both steric and electrostatic effects of side chains are responsible for the observed stereochemistry of the polymerization.

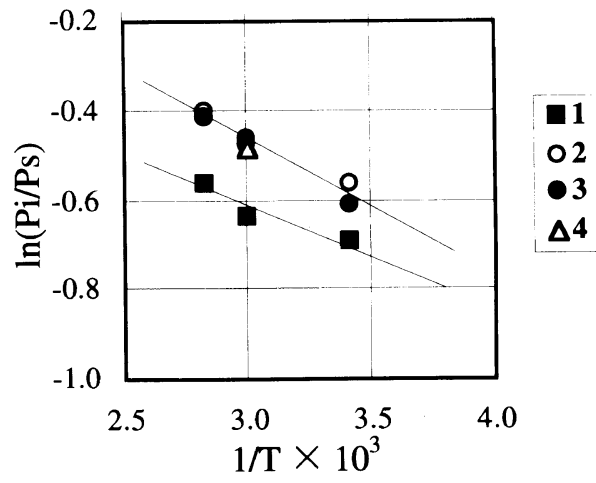

Figure 1. Temperature dependence of tacticity in the bulk polymerization of $1-4$
Figure 1 shows temperature dependence of tacticty in the polymerization of $\mathbf{1}-\mathbf{4}$ (Fordham plot $\left.^{14}\right)$. Differences in activation enthalpy and activation entropy between isotactic and syndiotactic propagations can be determined by the plots according to the following equation:

$$
\ln \left(P_{\mathrm{i}} / P_{\mathrm{s}}\right)=\left(\Delta S_{\mathrm{i}}^{\ddagger}-\Delta S_{\mathrm{s}}^{\ddagger}\right) / R-\left(\Delta{H_{\mathrm{i}}^{\ddagger}}^{\ddagger}-\Delta H_{\mathrm{s}}^{\ddagger}\right) / R T
$$

where $P_{\mathrm{i}}$ and $P_{\mathrm{s}}$ are mole fractions of isotactic and syndiotactic diads, respectively. For the polymerization of $1, \Delta H_{\mathrm{i}}^{\ddagger}-\Delta H_{\mathrm{s}}^{\ddagger}$ and $\Delta S_{\mathrm{i}}^{\ddagger}-\Delta S_{\mathrm{s}}^{\ddagger}$ were estimated to be $460 \mathrm{cal} \mathrm{mol}^{-1}$ and $0.2 \mathrm{cal} \mathrm{deg}^{-1} \mathrm{~mol}^{-1}$, respectively, and for the polymerization of $\mathbf{2}-\mathbf{4}, 620 \mathrm{cal} \mathrm{mol}^{-1}$ and 0.9 cal $\mathrm{deg}^{-1} \mathrm{~mol}^{-1}$, respectively. These values indicate that the higher syndiotactic specificity in the polymerization of $\mathbf{1}$ than that in the polymerizations of $\mathbf{2}-\mathbf{4}$ is due to entropy based on sterical factors.

\section{Solvent Effects on Polymerization Stereochemistry}

The stereochemistry of VTFAc and VPi polymerization is affected by polymerization solvents: $n$-alkane leads to higher syndiotactic specificity. ${ }^{5,9}$ To determine solvent effects on the polymerization of $\mathbf{1}$ and 2, polymerization was carried out using $n$-nonane, methanol, 1,2-dichloroethane, DMSO, acetone, and tetrahydrofuran (THF) as solvents (Table II). Polymerizations in THF gave polymers with lower $\bar{M}_{n}$ s than those in other solvents probably due to chain transfer to THF. The obtained polymers have poorer solubility in $n$-nonane, methanol, 1,2-dichloroethane, and DMSO than in acetone and THF, and polymerizations in these solvents except for runs 3 and 7 became heterogeneous. DMSO and acetone brought about lower syndiotacticity than other solvents, while the polymerizations in THF resulted in the highest syndiotactic specificity. Although solvent effects on stereochemistry were observed in this work, no clear relation was found between tacticity and solubility of the polymer in the solvents. The polymerization of 1 in THF at $0^{\circ} \mathrm{C}$ gave a polymer with $r=c a .69 \%(r r=47 \%)$ as evident from the ${ }^{1} \mathrm{H}$ NMR spectrum of the PVA derived

Table II. Radical polymerization of $\mathbf{1}$ and $\mathbf{2}$ in various solvents with $\mathrm{AIBN}$ at $20^{\circ} \mathrm{C}$ and $\mathrm{BPO}$ at $0^{\circ} \mathrm{C}^{\mathrm{a}}$

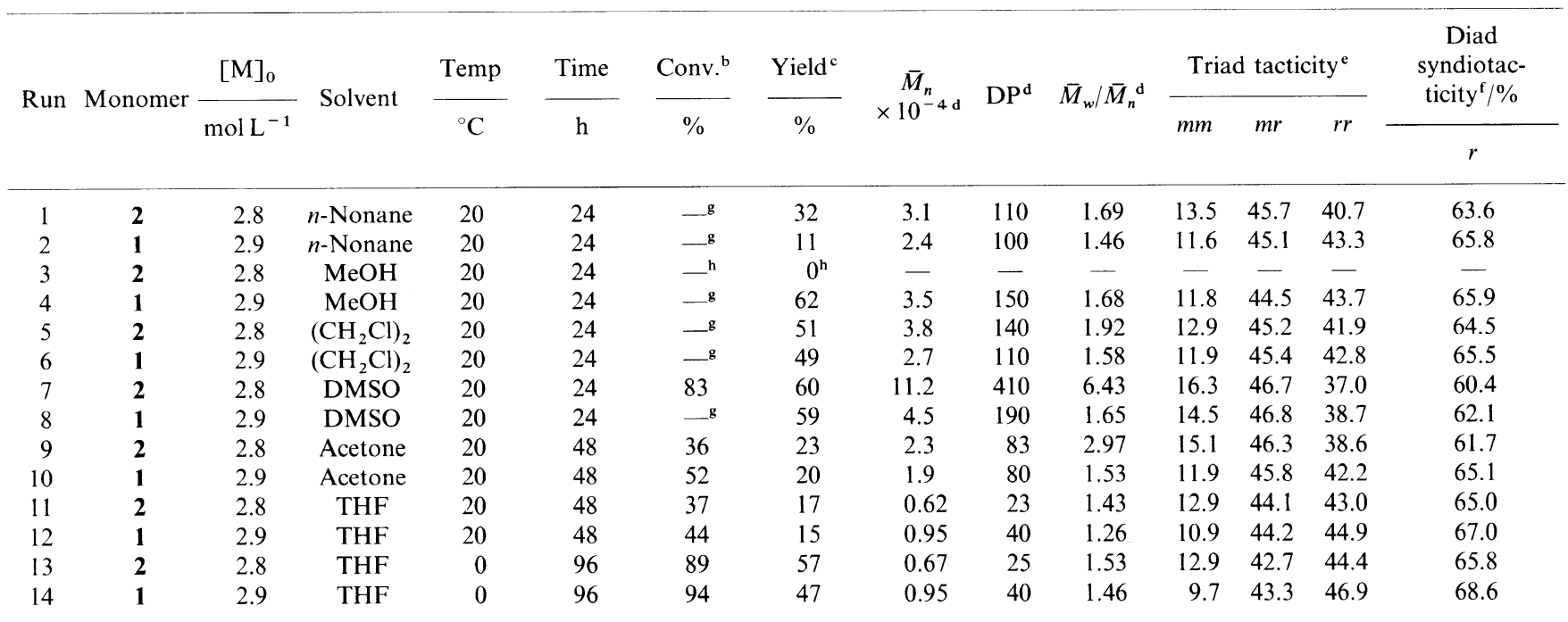

${ }^{\mathrm{a}}$ Under UV irradiation, $[\mathrm{AIBN}]_{0}=0.15 \mathrm{M},[\mathrm{BPO}]_{0}=0.15 \mathrm{M}$. ${ }^{\mathrm{b}}$ Determined by ${ }^{1} \mathrm{H}$ NMR analysis of reaction mixture in acetone- $d_{6}$. ${ }^{\mathrm{c}} n$ Hexane-insoluble part. ${ }^{\mathrm{d}}$ Determined by GPC (polystyrene standard) of original polymers in THF. ${ }^{\mathrm{e}}$ Determined by ${ }^{1} \mathrm{H}$ NMR of PVA in DMSO $-d_{6} .{ }^{\mathrm{f}}$ Calculated based on triad tacticity $(r+r r+m m / 2) . \quad{ }^{\mathrm{g}}$ Not determined because of phase separation during polymerization. ${ }^{\mathrm{h}}$ Solvolysis of 2 . 


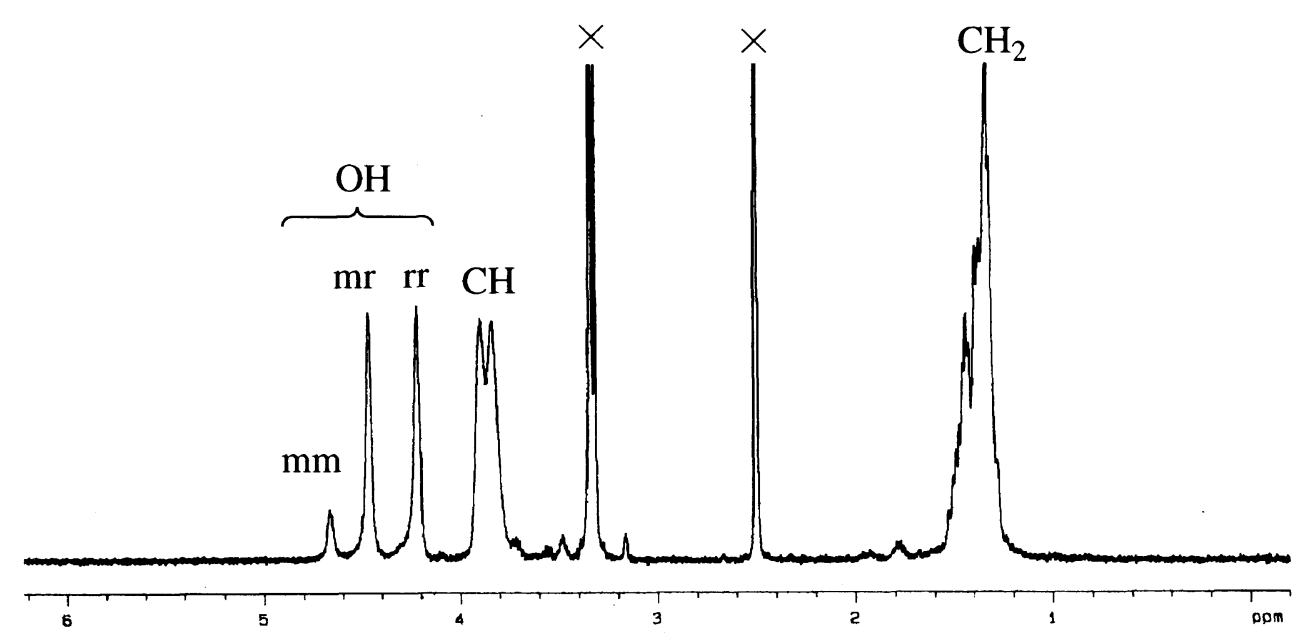

Figure 2. $400 \mathrm{MHz}{ }^{1} \mathrm{H}$ NMR spectrum of PVA derived from run 14 in Table II (DMSO- $d_{6}$, r.t.).

(a)

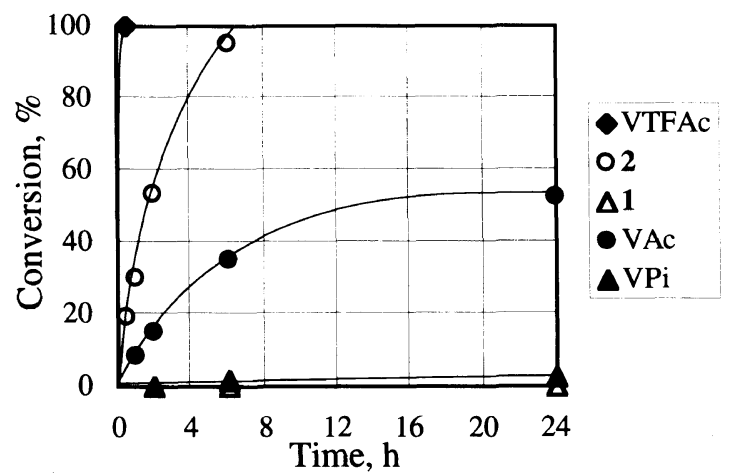

(b)

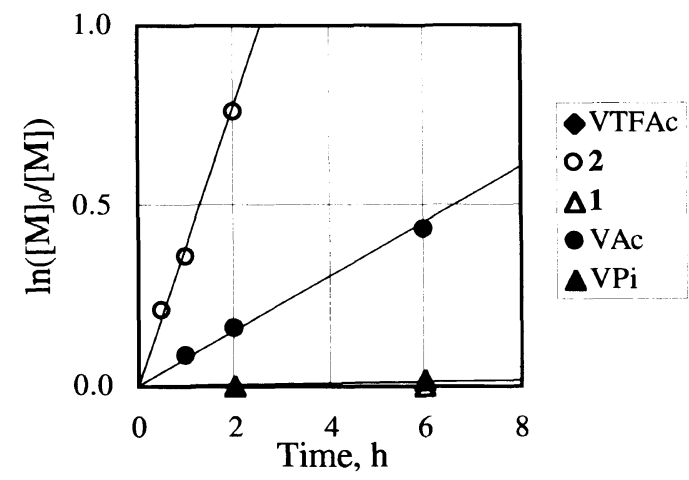

Figure 3. Time-conversion curves (a) and first order plots (b) for methanolysis of various vinyl esters.

from the poly-1 (Figure 2). This is the highest syndiotacticity reported for the free-radical polymerization of vinyl esters at $0^{\circ} \mathrm{C}$ or higher temperatures.

\section{Stability of Vinyl Esters and Poly(vinyl ester)s against Solvolysis}

Stability of the ester linkage in vinyl esters and their polymers is important and must be considered when a new monomer is designed. A monomer must be reasonably stable against solvolysis and its polymer must be readily saponified to give PVA. 2 was not strong enough against methanolysis to allow polymerization in methanol while 1 was successfully polymerized in methanol (runs 3 and 4 in Table II). In this connection, the methanolysis rates of VAc, VPi, VTFAc, $\mathbf{1}$, and $\mathbf{2}$ and the saponification susceptibility of the corresponding polymers were estimated. Figure 3 shows time-conversion curves and first-order plots for methanolysis reactions of monomers at $20^{\circ} \mathrm{C}$. Under the conditions used, the order of rate constants of methanolysis for the five monomers was $\operatorname{VTFAc}\left(>9.2 \mathrm{~h}^{-1}\right)>\mathbf{2}\left(0.39 \mathrm{~h}^{-1}\right)>\operatorname{VAc}\left(0.076 \mathrm{~h}^{-1}\right)>$ $\operatorname{VPi}\left(0.002 \mathrm{~h}^{-1}\right)>\mathbf{1}\left(<0.001 \mathrm{~h}^{-1}\right)$. The relatively high rate constants for VTFAc and 2 are probably due to the electron-withdrawing effects of fluorine atoms directly attached to the $\alpha$-carbon of the side chain. Bulky side chains of VPi and $\mathbf{1}$ may prevent interactions between methanol molecule and carbonyl group of monomers leading to relatively low rates of methanolysis.

Saponification of the polymers of VAc, VPi, VTFAc,
Table III. Saponification of various poly(vinyl ester) $\mathrm{s}^{\mathrm{a}}$

\begin{tabular}{|c|c|c|c|c|c|}
\hline \multirow[t]{2}{*}{ Run } & \multirow[t]{2}{*}{ Monomer } & \multirow{2}{*}{$\begin{array}{c}\text { Diad } \\
\text { syndiotac- } \\
\text { ticity } / \%\end{array}$} & \multirow{2}{*}{$\frac{\text { Conc. of } \mathrm{KOH}}{w \mathrm{t} \%}$} & \multirow{2}{*}{$\frac{\text { Time }}{\mathrm{h}}$} & \multirow{2}{*}{$\frac{\text { D.S. }}{\%}$} \\
\hline & & & & & \\
\hline 1 & VTFAc & 57 & 0.02 & 1 & 100 \\
\hline 2 & 2 & 62 & 0.02 & 1 & 0 \\
\hline 3 & 2 & 62 & 0.2 & 1 & 100 \\
\hline 4 & 1 & 66 & 0.2 & 1 & 88 \\
\hline 5 & VAc & 53 & 0.2 & 1 & 67 \\
\hline 6 & VAc & 53 & 0.2 & 4 & 91 \\
\hline 7 & VPi & 59 & 0.2 & 4 & 0 \\
\hline 8 & VPi & 59 & 5.0 & 4 & 25 \\
\hline
\end{tabular}

${ }^{\text {a }}$ Polymer $=1 \mathrm{mmol}$, with acetone $9 \mathrm{~mL}+\mathrm{KOH}$ soln. in $\mathrm{MeOH} 1 \mathrm{~mL}$, at $20^{\circ} \mathrm{C}$. ${ }^{\text {b }}$ Degree of saponification; determined by ${ }^{1} \mathrm{H}$ NMR in DMSO- $d_{6}$.

$\mathbf{1}$, and $\mathbf{2}$ was carried out in acetone with a small amount of $\mathrm{KOH}-\mathrm{MeOH}$ solution at $20^{\circ} \mathrm{C}$ (Table III). The order of saponification susceptibility was poly(VTFAc) $>$ poly$2>$ poly-1 $>$ poly $(\mathrm{VAc})>$ poly $(\mathrm{VPi})$. Poly-1 was more efficiently solvolyzed than poly(VPi) or poly(VAc) in spite of the high durability of monomer 1 against methanolysis. Although the reason for this observation is not clear at present, the results indicate that $\mathbf{1}$ is an excellent monomer which gives the syndiotactic polymer in alcoholic solvents, and the polymer is readily converted to PVA. 


\section{CONCLUSION}

The free-radical polymerization of VTFAc, VPi, and 1-4 was carried out and the stereochemistry of the polymerization was studied. Among the monomers, 1 gives the highest syndiotacticity. Polymerization strereochemistry is affected by temperature and solvent, and the syndiotactic specificity in the polymerization of $\mathbf{1}$ is enhanced to $c a .69 \%$ (diad) using THF as a solvent at $0^{\circ} \mathrm{C}$. Studies on saponification of the polymers and monomers disclosed that poly-1 is readily solvolyzed to give PVA while $\mathbf{1}$ is stable enough to allow polymerization in methanol.

Acknowledgments. This work was supported by NEDO for the project on Technology for Novel HighFunctional Materials in Industrial Science and Technology Frontier Program, AIST.

\section{REFERENCES}

1. For reviews, see; (a) K. Fujii, J. Polym. Sci., Macromol. Rev., 5, 431 (1971). (b) "PVA no Sekai (The World of PVA)," Kobunshi Kankokai, Kyoto, 1992.
2. K. Imai, T. Shiomi, N. Oda, and H. Otsuka, J. Polym. Sci., Part $A, 24,3225$ (1986).

3. T. Yamamoto, T. Yamamoto, J. Izumikawa, and M. Hirota, Kobunshi Ronbunshu, 36, 625 (1979).

4. U. Kador and P. Mehnert, Makromol. Chem., 144, 29 (1971).

5. S. Matsuzawa, K. Yamaura, H. Noguchi, and H. Hayashi, Makromol. Chem., 165, 217 (1973).

6. S. Matsuzawa, K. Yamaura, and H. Noguchi, Makromol. Chem., 168, 27 (1973)

7. S. Nozakura, M. Sumi, M. Uoi, T. Okamoto, and S. Murahashi, J. Polym. Sci., Polym. Chem. Ed., 11, 279 (1973).

8. R. Fukae, T. Yamamoto, Y. Fujita, N. Kawatsuki, O. Sangen, and M. Kamachi, Polym. J., 29, 293 (1997).

9. R. Fukae, T. Yamamoto, Y. Fujita, N. Kawatsuki, O. Sangen, and M. Kamachi, Polym. J., 27, 1257 (1995).

10. T. Nakano, K. Makita, and Y. Okamoto, Polym. J., 30, 681 (1998).

11. (a) E. N. Rostovskii, L. D. Budovskaya, A. V. Sidorovich, and E. V. Kuvshinskii, Vysokomol. Soedin., Ser. B, 9, 4 (1967). (b) I. A. Arbuzova, L. D. Budovskaya, V. N. Efremova, E. V. Kuvshinskii, E. N. Rostovskii, and A. V. Sidorovich, Kinet. Mech. Polyreactions, Int. Symp. Macromol. Chem., Prepr., 3, 249 (1969); Publisher: Akad. Kiado, Budapest, Hungary.

12. H. C. Haas, E. S. Emerson, and N. W. Schuler, J. Polym. Sci., 22, 291 (1956).

13. T. Yamamoto, S. Yoda, H. Takase, T. Saso, O. Sangen, R. Fukae, M. Kamachi, and T. Sato, Polym. J., 23, 185 (1991).

14. J. W. L. Fordham, J. Polym. Sci., 39, 321 (1959). 